\title{
Significance of taurine transporter (TauT) in homeostasis and its layers of regulation (Review)
}

\author{
STELLA BALIOU $^{1}$, ANTHONY M. KYRIAKOPOULOS ${ }^{2}$, MARIA GOULIELMAKI ${ }^{1}$, \\ MICHALIS I. PANAYIOTIDIS ${ }^{3,4}$, DEMETRIOS A. SPANDIDOS ${ }^{5}$ and VASSILIOS ZOUMPOURLIS ${ }^{1}$ \\ ${ }^{1}$ National Hellenic Research Foundation, 11635 Athens; ${ }^{2}$ Nasco AD Biotechnology Laboratory, \\ 18536 Pireus, Greece; ${ }^{3}$ Department of Electron Microscopy and Molecular Pathology, The Cyprus Institute of \\ Neurology and Genetics, 2371 Nicosia; ${ }^{4}$ The Cyprus School of Molecular Medicine, 1683 Nicosia, Cyprus; \\ ${ }^{5}$ Laboratory of Clinical Virology, Medical School, University of Crete, 71003 Heraklion, Greece
}

Received June 9, 2020; Accepted July 9, 2020

DOI: $10.3892 / \mathrm{mmr} .2020 .11321$

\begin{abstract}
Taurine (2-aminoethanesulfonic acid) contributes to homeostasis, mainly through its antioxidant and osmoregulatory properties. Taurine's influx and efflux are mainly mediated through the ubiquitous expression of the sodium/chloride-dependent taurine transporter, located on the plasma membrane. The significance of the taurine transporter has been shown in various organ malfunctions in taurine-transporter-null mice. The taurine transporter differentially responds to various cellular stimuli including ionic environment, electrochemical charge, and $\mathrm{pH}$ changes. The renal system has been used as a model to evaluate the factors that significantly determine the regulation of taurine transporter regulation.
\end{abstract}

\section{Contents}

1. Taurine synthesis

2. Taurine transport

3. Regulation of TauT transporter

4. Volume-insensitive and -sensitive taurine transport

5. Taurine deficient conditions

6. Taurine Transporter deficient mice (TauT KO)

7. Mitochondrial myopathy, encephalopathy, lactic acidosis and stroke-like episodes (MELAS) syndrome

8. Conclusions

Correspondence to: Dr Vassilios Zoumpourlis, National Hellenic Research Foundation, 48 Vas. Konstantinou Av., 11635 Athens, Greece

E-mail: vzub@eie.gr

Key words: taurine transporter, regulation, taurine deficient conditions

\section{Taurine synthesis}

Taurine (2-aminoethanesulphonic acid) is one of the major free $\beta$ amino acids, which is normally localized in high amounts in various mammalian tissues. It is believed that taurine exerts a wide range of physiological functions, including conjugation with bile acids (1), osmoregulation (2), antioxidation (3), neuronal development (4) and membrane stabilization (5). Many of the cytoprotective properties of taurine are based on its intracellular levels, which are dependent on its synthesis and transport and these processes are primarily controlled by the taurine biosynthetic enzymes cysteine dioxygenase (CDO), cysteine sulfinate decarboxylase (CSAD) and taurine transporter (TauT transporter) (6).

In most species, taurine is well-known as a non-essential amino acid, and its distribution is regulated through four key mechanisms: i) synthesis from methionine/cysteine; ii) intake from food in the intestine; iii) excretion as bile salt (taurocholate); and iv) unconjugated taurine in urine via the kidneys. The major site for taurine biosynthesis has been reported to be the liver (7), but it is also synthesized by plethora of other tissues like the brain (8), lungs (9), skeletal muscle (9), adipose tissue (10) and mammary glands (11) to a lesser extent. Endogenously, there are two distinct routes for taurine biosynthesis. Regarding taurine biosynthesis, methionine, or cysteine are the main substrates on which CDO and CSAD enzymes exert their action towards taurine biosynthesis (9). Initially, the CDO enzyme plays a key role in the oxidation of cysteine to cysteine sulfinic acid, on which CSAD enzyme displays its activity, converting cysteine sulfinic acid to hypotaurine and the last step is the transformation of hypotaurine to taurine (12). Alternatively, cysteine can be conjugated to coenzyme A (CoA), cysteamine is released during $\mathrm{CoA}$ turnover and cysteamine dioxygenase (ADO) enzyme converts cysteamine to hypotaurine (13). Besides, the dietary intake of cysteine has been considered as an important factor that affects taurine biosynthesis in the liver (7). In particular, a diet enriched with sulfur amino acids (methionine, cysteine) caused a 100-fold increase of CDO activity, without any alteration at the CDO mRNA levels, whereas CSAD activity and CSAD mRNA levels appeared 
to be compromised under these conditions (14). The results highlighted the ability of cysteine to upregulate CDO activity in the liver (9). Of great interest was the phenotypic outcome of cysteine dioxygenase deficiency (CDO KO) in mice, which developed severe taurine elimination and increased catabolism of cysteine to hydrogen sulfide instead of cysteine sulfinic acid formation, causing pulmonary and pancreatic toxicity $(15,16)$. Towards this direction, the importance of CSAD enzyme was confirmed, since third-generation (G3) of cysteine sulfinic acid decarboxylase deficient (CSAD KO) mice died within $24 \mathrm{~h}$ after birth and this result was avoided by the addition of $0.05 \%$ taurine added to the drinking water (17).

Since taurine biosynthesis is low in the vast majority of organisms, except for rabbits, intracellular taurine levels are maintained by taurine intake through the action of TauT transporter (18). TauT transporter mediates the translocation of taurine across tissues throughout the body, thus ensuring cytoprotection (19). The high taurine intake is balanced through two major pathways of taurine excretion. The first released form is in the urine, which is excreted by the kidney and the other one is taurine conjugated to bile acids, that are in turn released by the feces (20).

\section{Taurine transport}

Taurine biosynthesis is high during prenatal life and declines during adulthood with the lowest concentrations emerging normally in the elderly and also in certain pathologic conditions (trauma, sepsis) (13). Humans exhibit reduced activity of the biosynthetic enzyme CSAD and obtain the required amount of taurine from food (21). Taurine that derives from food is absorbed by the small intestine. Following absorption, active transport in the brush border membrane directs taurine to enterocytes, which can then deliver it to the portal vein (19). Then, taurine is imported to liver cells where taurine exerts its action, regulating hepatic metabolism, with the final step being the transport of taurine to circulatory cells. There are two types of transporters (TauT transporter or PAT1 transporter), that deliver taurine from hepatic tissue to different sites. The TauT transporter (SLC6A6 gene) is considered the major transporter, which is characterized by its dependence on ions (sodium or chloride), the high affinity and the low capacity against its substrates. On the contrary, the PAT1 transporter (SLC36Al) is considered as a proton-coupled/pH-dependent transporter, equipped with high capacity and low affinity for substrates. Several common features characterize both transporters. However, based on studies on their $\mathrm{Km}$ values, it has been shown that the concentration range of PAT1 $\mathrm{Km}$ is 7-4 $\mathrm{mM}$, whereas the values of TauT transporter $\mathrm{Km}$ is $(\mathrm{Km}$ $<60 \mu \mathrm{M})(22)$.

Concerning the localization of the two taurine transporters, TauT and PAT1, they are mainly localized on the plasma membrane. However, the location of taurine transporters in not limited to the cell membrane, but also expanded to the nucleus and other intracellular sites. The nuclear localization of taurine transporter potentially contributes to nuclear swelling/shrinking elicited by taurine $(23,24)$. When taurine is eliminated, using the competitive taurine uptake inhibitor $\beta$-alanine, the mitochondrial taurine content remains intact despite the total observed low taurine content (25), suggesting that taurine transporter can be also located in the mitochondria (26). In line with the above, at least one taurine transporter has been proven to be present in the mitochondria to import taurine (27). Furthermore, the PAT1 transporter has been reported to be localized on endosomal and lysosomal membranes (28).

From a structural perspective, it has been substantiated that TauT transporter has 12 hydrophobic transmembrane (TM) domains, with the $\mathrm{N}$ - and $\mathrm{C}$-terminal being exposed to the cytosolic compartment. In particular, sodium $\left(\mathrm{Na}^{+}\right)$and chloride $\left(\mathrm{Cl}^{-}\right)$are required for taurine transport, since these ions $\left(\mathrm{Na}^{+}\right.$and $\left.\mathrm{Cl}\right)$ bind to the first $\mathrm{N}$-terminal, extracellular loop (29), suggesting strong dependence of TauT transporter on ions. More precisely, one to three $\mathrm{Na}^{+}$ions are required to elicit taurine transport (30). The importance of sodium is confirmed through the fact that any reduction in the sodium gradient can disable further binding of taurine to TauT transporter (31). The ionic binding and the gating of taurine to TauT transporter relies on the presence of arginine (Arg-324) at the fourth intracellular segment of TauT transporter (32).

Researchers have examined the significance of TauT transporter using taurine-deficient models and they have shown that up to $90 \%$ reduction in taurine content takes place in most tissues, demonstrating that TauT transporter is the main non-redundant transporter for taurine and that PAT1 transporter was unable to compensate for the loss of TauT transporter (33). Many researchers have focused on the mechanisms that regulate the function of the TauT transporter, since a complete understanding of its regulation will provide compelling evidence on how to use taurine synergistically with other drugs for the identification of appropriate therapeutic strategies against complex diseases.

\section{Regulation of TauT transporter}

Various parameters determine the concentration of taurine: biosynthesis (9), TauT transporter activity (34), volume sensitive flux pathways (35), liver diseases (36), age (37), high-fat diet (HFD) (38), high-arginine diet (39), high/low-protein diet $(40,41)$ and ethanol-containing diet $(42)$. Taurine homeostasis at the organism level is controlled by multiple regulatory factors, it can essentially be categorized into taurine biosynthesis, absorption from intestinal cells and excretion from renal cells. Among them, the delivery of taurine from the extracellular to the intracellular environment is the most significant, which is mediated by the TauT transporter. TauT transporter belongs to a family of $\mathrm{Na}^{+} \mathrm{Cl}^{-}$-dependent transporters, which regulates taurine movement based on the ionic environment, electrochemical charge, $\mathrm{pH}$, and temperature (23).

Initially, taurine is transported across the brush-border membrane of the small intestine through the action of the TauT transporter and the $\mathrm{H}^{+} / a m i n o$ acid transporter 1 (22). The brush-border-mediated taurine uptake was generally proposed to be non-regulated; however, it was suggested that inflammation might increase taurine transport (43). Indicatively, lysophosphatidylcholine (44) and pro-inflammatory mediators (TNF $\alpha$, IL-1 $\beta$ ) (45) have been considered responsible for the regulation of TauT transporter. On the contrary, conditions such as type 2 diabetes have appeared to be of great importance for the downregulation of intestinal taurine absorption (46). 


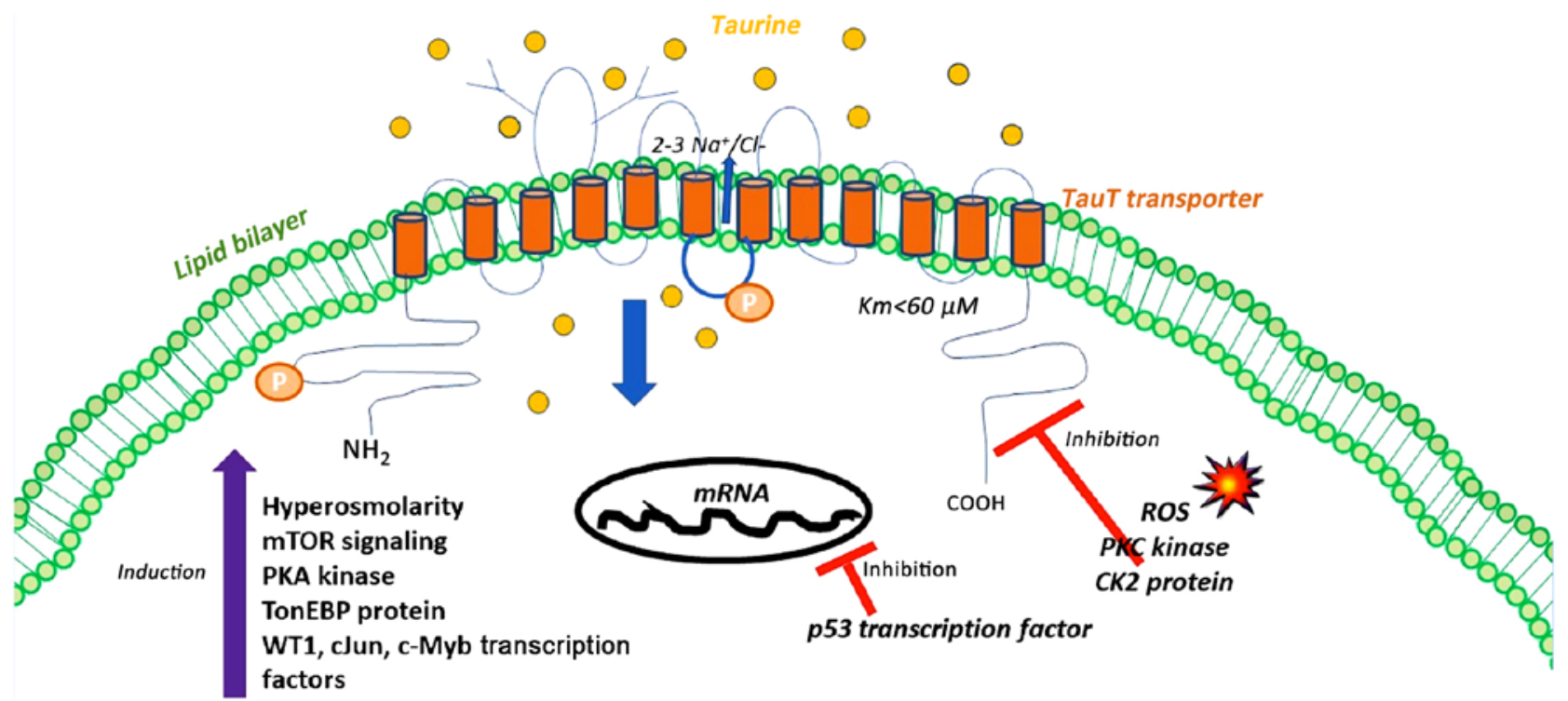

Figure 1. A representative scheme for the regulation of TauT transporter. The regulation of TauT transporter activity involves phosphorylation/dephosphorylation/oxidation of TauT or a putative regulator of TauT by protein kinases A and C (PKA, PKC), casein kinase 2 (CK2), hyperosmolarity and reactive oxygen species (ROS). Long-term regulation of TauT involves modulation of gene transcription by protein kinases (mTOR), transcription factors (WT1, cJun, c-Myb) and tonicity-responsive enhancer binding protein (TonEBP) or cell death signaling (p53 transcription factor).

In order to elucidate the determining factors for the regulation of taurine transport, we have used kidney as a model system. Interestingly, taurine's significance in renal cells was evidenced by the phenotype of the F1 generation of inbred taurine-deficient cats. Taurine was proven to be of outmost importance for renal cells, since its ablation lead to kidney damage (47). Upon taurine deficiency, dysregulated differentiation of epithelial cells, enlarged glomeruli, and ureteral dilatation were observed (47).

There are multiple distinct levels of TauT transporter regulation. Taurine transporter is a membrane-bound channel and its distribution appears to adapt to taurine levels, sharing common features with the ligand-dependent receptor (48). Renal reabsorption of taurine ranges from 40 to $99.5 \%$ as opposed to reabsorption of most amino acids (98-99\%). As a general note, TauT transporter expression is ubiquitous (49), due to the acknowledged function of taurine as an organic osmolyte (50). The main function of TauT transporter is osmoregulation which contributes to cell volume regulation, utilizing a chemiosmotic $\mathrm{Na}^{+}$gradient to couple 'downhill' transport of $\mathrm{Na}^{+}$with 'uphill' transport of taurine across the membrane (51), under isotonic and hypertonic conditions (52). The external to internal downhill $\mathrm{Na}^{+} / \mathrm{Cl}^{-}$gradient determines the uptake of taurine from cells through the action of TauT transporter and taurine is moved through the following stoichiometry $2 \mathrm{Na}^{+}: 1$ taurine: $1 \mathrm{Cl}^{-}$, according to Hill model (53). In this way, sodium has been highlighted as the cation that plays a determinant role in the renal adaptive response of TauT transporter (54), showing that there are no other cations that are sufficient to replace the importance of sodium for taurine transport (Fig. 1). Another research group has highlighted the importance of chloride for taurine transport, considering that chloride ions facilitate the binding of the second sodium to TauT transporter (53). The same research group has supported that bromide can partially compensate for the lack of chloride, aiding taurine uptake (55). In order to maintain the normal cell volume, sodium is pumped out of the cell by the $\mathrm{Na}^{+}$ $\mathrm{K}^{+}$-dependent ATPase, as shown in Ehrlich ascites tumor cells (EATC) (56). Even though sodium or chloride ions are important in taurine transport, these ions do not play the most determinant role in regulating taurine transport. These ions are crucial for the maintenance of the electrochemical gradient, which in turn determines proper taurine transport. Besides, taurine transport is a stereospecific and membrane surface-specific procedure. In support of this, taurine transport can be suppressed only by the presence of other $\beta$-amino acids and $\beta$-aminobutyric acid (GABA) but not by $\alpha$-amino acids (57).

Taurine concentration has also been classified as a factor of great importance for the regulation of TauT transporter. The type of regulation was clarified in two continuous renal epithelial cell lines, porcine kidney-proximal tubule cells (LLCPK1) and Madin-Darby canine kidney, mainly distal tubule cells (MDCK), in which augmented taurine uptake was observed in taurine-deficient conditions. When low taurine concentrations occurred, the activity of TauT transporter was upregulated to compensate for the loss of intracellular taurine levels and consequently taurine reabsorption occurred through circulation through the renal tubules (58). In contrast, taurine-rich conditions led to reduced taurine transport as compared to cells cultured in normal medium (47). Importantly, the transcription of TauT reporter was reduced in response to excess taurine whereas any alteration in the transcription of taurine biosynthetic enzymes (CDO, CSAD) was not observed (47).

Polarity has been acknowledged as another factor capable of influencing TauT transporter regulation. For example, MDCK cells mediated taurine transport across their basolateral surface rather than the apical surface (59). In particular, TauT transporter expression was accumulated in the apical surface of LLC-PK1 cells compared to MDCK cells (60-62). In this manner, LLC-PK1 cells transported taurine from the apical to the basolateral surface whereas MDCK cells 
directed taurine transport from the basolateral surface into the cells. The main principle for that renal adaptive response was the response of cells to existent osmoregulatory needs. At the molecular level, the underlying transcription factor that determined the appropriate taurine transport was the tonicity-responsive enhancing binding protein (TonEBP), which was recruited to the promoter region (tonicity response element-TonE) of the TauT transporter gene. In support of the above, Handler and Kwon (63) reported that the protein expression of TauT transporter was enriched under hyperosmolar stress conditions (like extracellular administration of sucrose or raffinose), in which TonEBP protein was recruited to the tonicity response element (TonE) (64). When elevated synthesis of TauT transporter was observed in response to hyperosmolar conditions, taurine transport within the cell was increased (65). Considering that hypertonicity conditions are present within cells, the transactivation capacity of TauT transporter gene was activated through the binding of TonEBP protein to the TonE site of TauT transporter promoter (65). In this sense, the tonicity-responsive enhancer-binding protein (TonEBP/NFAT5) binds to the tonicity response element (TonE) in the promoter region of the TauT transporter gene (65), proposing that TauT transporter is dependent on the recruitment of TonEBP protein to its promoter, following hypertonic exposure. Since, mTOR facilitates transcription of several osmostress response genes including TonEBP (66), it has been proposed that elevated TauT activity is derived from an increased mTOR-dependent TonEBP activity upon hypertonic response (2). For example, the mTOR signaling cascade has been proposed as a determinant factor for augmenting the activity of TauT transporter in primary human trophoblasts (67), non-malignant NIH3T3 and carcinoma Ehrlich ascites (ELA) mouse fibroblasts (2), thereby increasing the activity of TauT transporter following hypertonic exposure (2). In contrast, inhibition of the mammalian target of rapamycin mTOR has been reported to downregulate TauT mRNA abundance, translation, as well as TauT activity in primary human trophoblasts (67), non-malignant NIH3T3 and carcinoma Ehrlich Lettre ascites (ELA) mouse fibroblasts (2). In line with the above, the tonicity susceptibility of taurine biosynthetic enzymes (CDO, CSAD) has been observed but to a lesser extent compared to that of TauT transporter. Therefore, the TonE/TonEBP system appears to be an essential mechanism in regulating cell volume in hyperosmolar conditions through mTOR signaling, causing the activity of TauT transporter to be increased (Fig. 1).

Furthermore, the transcription levels of the TauT transporter are under the control of p53 and c-Jun transcription factors, which are commonly implicated in renal damage induced by chemotherapeutic drugs (68). The balance of this regulation determines the rate of synthesis of TauT transporter protein, thereby influencing the fate of renal cells (68). Indeed, WT1, c-Jun, and c-Myb potentiate TauT transporter expression whilst the p53 tumor suppressor gene hinders TauT transporter expression (68) (Fig. 1). The inverse association of TauT transporter with p53 explains the way by which renal cells are protected from cisplatin-induced nephrotoxicity, suggesting the cytoprotective role of taurine against renal side effects induced by cisplatin (68). In particular, transgenic TauT transporter mice have been shown capable of bypassing cisplatin induced renal dysfunction, potentially through suppressing the p53 signaling pathway rather than altering the cisplatin delivery, as it was indicated at both in vitro and in vivo settings (69). The results were in line with previous ones that have supported that the phenotype of TauT transporter deficient mice was identical to phenotypes from either taurine-deficient kittens or transgenic p53 mice because TauT transporter constitutes a transcriptional target of p53 (47). It is worth noting that regulation of TauT transporter takes place in S3 fragments of renal proximal tubule cells where cisplatin exerts its action, given that surviving renal proximal tubule cells are considered of crucial importance in maintaining normal renal function following acute kidney injury (70). During renal development, TauT transporter is transcriptionally regulated by WT1 and Sp1 whereas the p53 transcription factor is the crucial modulator of TauT transporter in case of kidney injury (47). The response of renal cells to the nephrotoxic chemotherapeutic agent (cisplatin) is dependent on the regulation of TauT transporter transcription (69). As a result, the functional TauT transporter gene plays a determinant role, protecting renal cells from cisplatin-induced damage. Since then, other researchers have shown that taurine ameliorates the symptoms of renal dysfunction mediated by cisplatin, through its anti-inflammatory and anti-oxidant properties (71).

Apart from the significance of TauT transporter in overcoming cisplatin resistance through its interaction with p53 tumor suppressor protein, TauT transporter transactivation capacity has been suggested to be reduced by doxorubicin-induced activation of p53 (72). In this way, researchers have examined how transcriptional regulation of TauT transporter affected the response of cancer cells to chemotherapeutic drugs. For example, researchers have provided convincing evidence that human breast cancer MCF-7 TauT transporter-deficient cells were vulnerable to chemotherapeutic drug-induced apoptotic effects (72). Along with in vitro results, the in vivo experiments proved that the phenotype of heterozygous p53 mutant $\left(\mathrm{p} 53^{+/}\right)$and $\mathrm{p} 53$

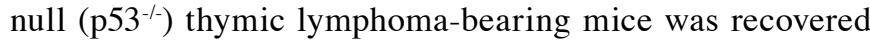
using TauT transporter vaccine, causing prolonged survival of tumor-bearing mice by 1.5 -fold (72). Therefore, the TauT transporter vaccine has been proposed as a new therapeutic option to forestall cancer growth both in in vitro and in vivo conditions, independent of the p53 transcriptional status (72).

Besides, the reduced activity of TauT transporter may be the direct result of either activation of the tumor suppressor protein p53 or treatment with high extracellular taurine levels (23) or hypotonicity (73) (Fig. 1). It is commonly accepted that increased taurine intake is accompanied by the downregulation of TauT transporter, in order to respond to the changes of chemical gradient and to maintain the cell volume (49). In this context, many studies have revealed that the activity of TauT transporter is under the control of acidification, incubation with oxidative molecules [reactive oxygen species (ROS)] (73) and osmotic cell swelling $(56,73)$. Importantly, the transport of taurine is regulated by phosphorylation signaling cascades. The amino acid sequence of TauT transporter contains several putative consensus sites for phosphorylation through $\mathrm{Ca}^{2+} /$ diacyglycerol-dependent protein kinase C (PKC) and cAMP-dependent protein kinase A (PKA) within the intracellular domains. In particular, the maximal 
activity of TauT transporter was inhibited in a wide range of cells through stimulation of the serine/threonine kinase protein kinase $\mathrm{C}$ (PKC) activity $(23,74-76)$. Moreover, PKC is sufficient to mediate phosphorylation at Ser-332 residue of TauT transporter, which in turn neutralizes ionic binding of taurine to Arg-324 and abolishes the activity of TauT transporter, through structural conformational changes (23). Accordingly, it has been reported that the effect of cAMP-dependent protein kinase A (PKA) is eradicated following PKC activation since PKA activation is required for $\mathrm{Na}^{+}$-dependent taurine uptake by cells $(30,74)$. The fourth segment of the TauT transporter contributes to taurine propagation across the cell membrane due to PKC phosphorylation at serine $322(50,60,77)$. In line with these data, casein kinase 2 (CK2) has been demonstrated to inhibit the activity of TauT transporter, presumably through phosphorylation at Thr-28. When CK2 is suppressed, TauT transporter affinity is promoted towards sodium and the $\mathrm{Na}^{+} /$taurine stoichiometry for taurine transport is suppressed (Fig. 1) (76).

Hence, taurine transport can be regulated by hypoxia. The effect of hypoxia on the activity of TauT transporter has been documented in brain microvascular endothelial cells (blood-brain barrier, BBB) since hyperglycemia accounts for the loss of microvascular barrier integrity (78-80). Researchers examined the association of TauT transporter with hypoxia-inducible factor-1 (HIF-1), which is the major causal factor for the induction of $\mathrm{BBB}$ disruption and increased BBB permeability $(81,82)$, and is also related to diabetic retinopathy or neuropathy through vascular endothelial growth factor (VEGF) upregulation (83). Moreover, it should be taken into consideration that PKC kinase exerts its regulatory activity on both VEGF and TauT transporter $(32,84)$.

So, researchers proved that brain vascular endothelial cells exhibited high expression levels of HIF-1 and VEGF, by reducing the activity of TauT transporter in high-glucose conditions. The results were confirmed when HIF-1 inhibitors rescued BBB cells from hypoxia due to TauT transporter upregulation (78).

In addition to changes in osmolarity, hyperglycemia and oxidative stress conditions have also been reported to modulate gene expression of TauT transporter. Interestingly, transcriptional levels of TauT transporter were induced in healthy subjects, as compared to type 1 diabetes patients, accompanied by low plasma homocysteine levels (85). In another study, mononuclear peripheral blood cells of patients bearing diabetic retinopathy were characterized by reduced TauT transporter expression (86). In line with the above, an outstanding study provided convincing evidence that taurine status determined the development of diabetic nephropathy in diabetic animal models. The underlying concept relied on three lines of evidence: i) taurine deficiency was apparent in diabetic patients (46); ii) taurine excess provided protection against acute kidney injury (87); and iii) taurine provided cytoprotection against high-glucose-induced oxidative stress, through preventing protein carbonyl content (88). Accordingly, the upregulation of TauT transporter in diabetic conditions was also observed in fat tissues from obese mice caused by a high-fat diet or genetic mutations ( $o b / o b$ and $d b / d b$ mice). Following in vivo observations, the commitment of human adipose-derived stem cells (hASCs) to adipogenic progenitors was only promoted, when TauT transporter levels were high. Among the molecules that are regulated by TauT transporter, hypotaurine and $\beta$-alanine promoted adipocyte formation, whereas taurine inhibited the process. In this manner, it was proved that impaired hASCs differentiation accompanied by eliminated TauT transporter activity was recovered by hypotaurine and $\beta$-alanine through impeding $\beta$-catenin transcriptional transactivation. The results proposed that taurine transport can act as a new therapeutic strategy against obesity (89). Additional evidence supporting the functional importance of TauT transporter in diabetes, emerged through the phenotype of TauT transporter deficient animal models, in which researchers observed that characteristics of TauT transporter null animals comprised mesangial cell expansion, glomerular basement thickening, nodular sclerosis with expansion of the glomerulus beyond Bowman's capsule, and juxtaglomerular tuft sclerosis (90). Since, typical features of human diabetic nephropathy involved changes in ischemic heart, atherosclerosis induction, glomerular dropout, and interstitial fibrosis, it was plausible that TauT transporter null mice mimicked human diabetic nephropathy. Histologically, TauT transporter null mice presented increased deposition or abundance of SMA, collagen IV, CD34 (as a marker of endothelial injury), and $\mathrm{Ki} 67$.

A large number of studies have suggested that taurine transport may be enhanced by inflammation (45). It has been highlighted that inflammatory cytokines contribute to the induction of TauT transporter activity to maintain taurine levels. Interestingly, intestinal epithelial cells increased TauT transporter levels to respond under inflammatory conditions. For example, anti-inflammatory properties of taurine were manifested through the regulation of TauT transporter in leukocytes of patients with depression. It was observed that the antidepressant mirtazapine diminished $\mathrm{CD} 4^{+} \mathrm{T}$ and $\mathrm{CD} 8^{+}$ $\mathrm{T}$ leukocytes that contained TauT transporter to 77 and $80 \%$, respectively. Notably, TauT transporter distribution in all cells did not change following anti-depressant therapy, suggesting that reduced taurine transport in circulating immune specific leukocytes potentially accounted for high extracellular taurine content, which might be involved in protection against oxidants and inhibition of pro-inflammatory cytokine-mediated damage through the formation of $\mathrm{N}$-Chlorotaurine ( $\mathrm{TauCl})(91)$.

\section{Volume-insensitive and -sensitive taurine transport}

During isotonic conditions taurine is released to the extracellular compartment, and it is upregulated when cholesterol-depleting agents (92), lysophosphatidylcholine (93) are administered, and during the apoptotic process (94). The release of taurine in unstimulated cells through the action of TauT transporter does not seem feasible, considering the low intracellular sodium (94). On the contrary, taurine can be released via TauT transporter, as observed in Ehlrich ascites tumor cells (EATC) in response to arachidonic acid/eicosapentaenoic acid (95), prostaglandin $\mathrm{E}_{2}$ (96) or cisplatin (94) which increased the sodium conductance.

Increased release of taurine via the volume-sensitive taurine release pathway, designated volume-sensitive organic 
anion channel (VSOAC) has been observed following hypotonic exposure. The threshold for the activation of taurine release has been estimated at 15\% of cell swelling in NIH-3T3 cells, and there is a positive relationship between efflux and reduced osmolality in an exponential manner (97).

\section{Taurine deficient conditions}

To determine the functional significance of taurine, models of taurine deficiency have been developed by knocking out the TauT transporter gene $(33,98)$ nutritional depletion, an inhibitor of taurine intake, such as taurine transporter antagonist (guanidinoethane sulfonate) (99) or $\beta$-alanine (100) and carbon tetrachloride $\left(\mathrm{CCL}_{4}\right)(101)$, all of which contribute to the elimination of taurine values. For example, taurine transport inhibitor ( $\beta$-alanine) can cause the elimination of mitochondrial taurine content by $60 \%$ after supplementation with $\beta$-alanine (100).

\section{Taurine Transporter deficient mice (TauT KO)}

Towards delineating the impact of taurine on the cardiac muscle, researchers proceeded to the elimination of taurine transporter, generating TauT KO mice. In one case, Ito et al managed to ablate exons 2-4 of TauT transporter, causing a decrease in taurine in both cardiac and skeletal muscle, respectively, of 100 and 96\% (98). In another case, Heller-Stilb et al (33) generated TauT KO mice by elimination of exon 2 of taurine transporter. Similarly, the phenotype of latter TauT KO mice showed a decrease at cardiac and muscle taurine levels at a rate of $98 \%$. They developed a mouse model with a disrupted gene encoding the taurine transporter $\left(\mathrm{TauT}^{\prime-}\right)$ and observed that higher amounts of taurine loss occurred in skeletal muscle and heart (95\% decrease), followed by lower amounts of taurine plasma, kidney, liver, and the eye ( $74 \%$ decrease). Interestingly, the mice presented severe retinal degeneration due to vision loss (33). Undoubtedly, in both cases, there was a remarkable decline of taurine and abnormal function in tissues in which taurine is necessary. More specifically, the phenotypic characteristics of TauT KO mice were: lower body weight, exercise intolerance and muscle atrophy $(98,102)$, loss of retinal photoreceptor function, reduced responsiveness to nociceptive stimulation (103), degeneration of their inner ear, alteration of renal development and function, unspecific hepatitis/liver fibrosis and cardiomyopathy $(87,104)$, as well as reduced T-cell memory generation (105) and blunted apoptosis in erythrocytes accompanied by alterations in the balance of blood cells (91). All the disturbances in different organs were exacerbated with aging, implying the regulation of taurine transporter during aging. Based on the above, we can conclude that the intracellular taurine levels in cardiac and skeletal muscle are dependent on taurine transport activity. However, Warskulat et al (102) contributed to causing a debate regarding the phenotype of TauT KO mouse models, because TauT KO mice had a normal function with high susceptibility towards heart failure, as indicated by high expression of fetal genes such as atrial natriuretic peptide (ANP), and brain natriuretic peptide (BNP). Consequently, taurine is fundamental in cardiac homeostasis and the differential results of deficiency ultimately depend on the genetic background of the animal models used. Focusing on the generation of former TauT KO mouse models, it was observed that signs of dilated cardiomyopathy (levels of ANP, BNP) were more intense in 9-month-old TauT KO mouse models compared to 5-month-old TauT KO animals, implying the regulation of taurine in age-sensitive manner (98). In general, TauT KO mice exerted high percentages of necrotic cells and disorganization of myofilaments in skeletal muscle (104).

Studies from TauT KO mice proved that low intracellular taurine levels caused a variety of dysfunctions in different organs in an age-dependent way (14-20). Within 1 year after birth, TauT KO mice manifested vision, suffered from auditory, olfactory malfunctions accompanied by muscle impairment, and altered synaptic transmission in the brain (21). At greater age (beyond 15 months), TauT KO mice presented liver manifestations, such as fibrosis, unspecific hepatitis, and tumor formation through lowering mitochondrial respiratory chain activity $(17,21)$. Even though earlier studies have reported the great implication of TauT transporter in hepatocytes, the latest studies highlighted that TauT transporter was crucial in hepatic non-parenchymal cells $(56,57)$. Interestingly, differences in the taurine distribution of TauT KO mice were observed, underscoring the complete taurine loss in Kupffer and sinusoidal endothelial cells but not in parenchymal cells (106). For instance, hepatic parenchymal cells of TauT KO mice presented a decline of Tau transporter by $30 \%$, whereas hepatic non-parenchymal cells of TauT KO mice had a marked decline of TauT transporter (52).

Furthermore, the research team led by Häussinger provided convincing evidence for the presence of apoptotic cells in taurine-transporter deficient tissues. Apoptosis emerged in photoreceptor cells, leading to taurine transporter deficient mice to blindness at an early age, given that the differentiation of cells was not closely dependent on taurine transporter. Accordingly, the olfactory receptor neurons of TauT KO mice followed the same apoptotic trend, displaying signs of immaturity. Importantly, taurine caused hepatocyte destruction which was manifested by a high proportion of hepatic apoptotic cells, thereby leading moderate unspecific hepatitis and liver fibrosis in TauT KO mice beyond 1 year of age (107).

For many years, researchers were not able to reveal the mechanisms underlying structural liver dysfunction in aged TauT KO mice. Recently, Qvartskhava et al (108) provided the instructive principles of taurine loss by which liver dysfunction of TauT KO mice emerged. Researchers attributed the liver malfunction of TauT KO mice to altered hepatic ammonia handling and hepatic glutamine synthesis in a time-dependent manner. In particular, it was suggested that TauT transporter deficiency disturbed ammonia detoxification by perivenous scavenger cells in the liver, thereby inducing systemic hyperammonemia through impaired hepatic glutamine synthesis. The underlying mechanisms varied according to the age of TauT KO mice. That was reflected by the inactivation of the ammonium transporter rhesus type glycoprotein B (RhBG) in 3-month-old TauT KO mice and a tyrosine nitration-mediated elimination of glutamine synthesis at 12-month-old because of oxidative/nitrative stress. The results of the 3-month-old TauT KO mice could be explained, taking into consideration that hepatic RhBG 
expression is restricted to glutamine synthetase-expressing hepatocytes. As a result, 3-month-old TauT KO mice indirectly impaired glutamine synthesis and doubled the ammonia concentration required for half maximal glutamine synthesis while 12-month-old TauT KO mice directly disturbed glutamine synthesis.

Concerning the effects of taurine elimination in the myocardium, H NMR spectroscopy experiments substantiated that TauT KO mice presented significant taurine loss, rendering them energy starved. In that sense, taurine elimination was responsible for cardiomyopathy with concomitant cardiac atrophy, which was manifested by remarkable signs of cardiac myofibrillar fragmentation, mitochondrial disruption, and swelling of the outer mitochondrial membrane $(98,100,102)$. In support of the above, the results of liquid chromatography-mass spectrometry (LC-MS) distinguished the range of metabolites that were present between the hearts of wild-type and taurine transporter deficient mice. Initially, it was observed that there was no difference in taurine-modified bile acids, comprising taurocholate, taurodeoxycholate, and taurohyocholate and those findings were consistent with previous ones (106). Importantly, mass spectrometry classified a great number of metabolites that were differentially distributed in the hearts of $\mathrm{KO}$ or wild-type mice. As expected, methionine levels were elevated in TauT $\mathrm{KO}$ hearts probably due to protein turnover, since methionine is required for taurine biosynthesis (109). The identification of differential metabolites derived from two groups provided the information that impaired fatty acid oxidation and dysregulated osmoregulation were the prevalent consequences of taurine elimination. For the maintenance of organic osmolyte homeostasis, the amino acid transporter Slc38a 2 and betaine, as well as glycerophosphocholine, were found to be enriched in the hearts of taurine transporter deficient mice compared to hearts of control mice. Notably, Slc38a 2 constituted a transporter of glutamine, proline, alanine (110) and it was stimulated upon hypertonic exposure, through the action of NFAT5/TonEBP transcription factor (98). TauT transporter was upregulated via NFAT/TonEBP in hypertonic stress conditions, with the ultimate aim of regulating intracellular osmolytes $(65,111)$. Consistent with the above, betaine and glycerophosphocholine were of utmost importance in regulating the concentrations of organic osmolytes (112). Therefore, these constitute irrefutable evidence that the enrichment of the molecules was to compensate for the taurine deficiency, thereby restoring the defect in intracellular levels of osmolytes.

Taurine is essential not only for the maintenance of organic osmolytes but also for fatty acid metabolism. As expected, analysis of metabolites derived from TauT KO hearts indicated that there was an inhibition in $b$ oxidation of fatty acids and in the Krebs cycle $(100,113)$. Specifically, dysfunctional mitochondrial respiration was shown by downregulation of long-chain acyltaurines and upregulation of short-chain acyltaurines in TauT KO hearts (109). Consistent with the central role of taurine in the respiratory chain, it was reasonable that TauT KO mice displayed impaired complex I activity, accompanied by dysfunctional NADH dehydrogenase. Mass spec results confirmed the significance of taurine in mitochondria, showing that TauT KO hearts had high levels of NADH due to inactivation of NADH dehydrogenase and acetylcarnitine, which was contributed to inefficient use of acetyl CoA as a substrate in citric acid cycle (109). Metabolome analysis also provided an interesting explanation concerning the phenotype of old TauT KO mice (beyond 15 months), that displayed symptoms of chronic liver disease (106). Urea metabolites (ornithine, citrulline, and arginosuccinate) prevailed in TauT $\mathrm{KO}$ hearts, that were probably released from the surplus of hearts to livers of TauT KO mice. Additional search related to heart changes of taurine loss proved that the hearts of $\mathrm{KO}$ mice presented significant alterations in their glutathione metabolism, as indicated by higher amounts of pyroglutamate and undetectable levels of glutamyltaurine, compared to normal hearts. These results were expected given that there is a competitive relationship between pyroglutamate and glutamyltaurine (114).

Given the osmoregulatory activity of taurine, its anti-oxidant activity, and its capacity to maintain protein folding/phosphorylation, it is reasonable to suggest that taurine not only plays a key role in cellular homeostasis, but it also potentially contributes to the rescue of the organism from the aging process. However, there is only a small number of studies that support the beneficial action of taurine on health, modulating skeletal muscle senescence, and protein folding. In this direction, Ito et al (116) observed a couple of aging-related functional defects in skeletal muscle of (TauT KO mice aged 18 to 22-months). At a rapid pace, the mice developed aging-related hallmarks that were evidenced by diminished mitochondrial complex I activity and excessive formation of muscle fibers with central nuclei, implying the contribution of taurine loss to sarcopenia. Taurine deficiency in aged mice caused a decline in respiratory chain complex 1 activity, accompanied by an enhancement in unfolded protein response (URP) and in Cyclin-dependent kinase 4 inhibitor (p16INK4a), which constitutes an aging biomarker (115). Specifically, it was observed that aged TauT KO mice displayed increased levels of p16INK4A up to 10 times compared to aged wild-type mice. Similar enrichment of p16INK4A was observed in the lung and kidney of aged TauT KO mice to a lesser extent compared to that of skeletal muscle of aged TauT KO mice. There was no difference in p16INK4A protein content between young wild-type and TauT KO mice, suggesting that a pronounced increase in p16INK4A protein content was tightly related to aging (116). Furthermore, aging was related to taurine loss through their effect on UPR signaling cascades which served as a protective response against ER stress. Both aging and taurine deficiency was reported to display decreased GRP78 expression and downregulation of several ER membrane sensor proteins (PERK, eIF2 $\alpha$, IRE $\alpha$ ) that are associated to UPR. Our current findings in the taurine-depleted hearts show a close resemblance to accelerated aging $(117,118)$, ER $(119,120)$. As a consequence, taurine deficient and aged hearts seemed to be very susceptible to accumulating oxidation-mediated protein aggregates (121). Transcriptome data derived from the skeletal muscle of old TauT $\mathrm{KO}$ mice revealed induction of SMAD3 and $\beta$-catenin signal transduction pathway compared to old wild-type mice (122).

\section{Mitochondrial myopathy, encephalopathy, lactic acidosis and stroke-like episodes (MELAS) syndrome}

The normal development of animals is dependent on adequate taurine levels. Interestingly, if animals were fed 
with a taurine-deficient diet, they would exhibit a plethora of malfunctions: metabolic and endocrine changes and renal dysfunction. The underlying cause of abnormalities was attributed to impaired biosynthesis of mitochondria-encoded protein subunits of the respiratory chain complexes, resulting in disturbed electron transport flux. Essentially, the biosynthesis of mitochondria-encoded protein subunits of the respiratory chain complexes exhibited an absolute dependence on a specific post-translational modification, which is manifested at tRNA Leu (UUR), contributing to the formation of 5 taurinomethyluridine-tRNA Leu (UUR). When animals were fed a taurine-deficient diet, the formation of mitochondrial 5-taurinomethyluridine in the wobble position of tRNA Leu (UUR) was hindered due to loss of taurine which was used as a substrate for the post-translational modification of the uridine base in the wobble position. As a result, the production of mitochondria-encoded protein subunits of the respiratory chain complexes was prevented, given that the electron transport chain subunits contained multiple UUG codons, directed for the translation of leucine and lysine residues (123). Interestingly, it is worth mentioning that MELAS (mitochondrial myopathy, encephalopathy, lactic acidosis, and stroke-like episodes) is a mitochondrial disease that might be caused by impaired UUG decoding, which is often observed in taurine-deficient conditions (124). Following extensive research, it was suggested that there were no significant differences between the phenotype of MELAS syndrome and taurine deficiency since MELAS symptoms are nearly indistinguishable from those of taurine deficiency. In MELAS conditions, impaired UUG decoding, diminished respiratory chain flux accompanied by decreased adenosine triphosphate (ATP) synthesis, superoxide anion overproduction and stimulation of anaerobic metabolism were observed, thus essentially impairing the viability and functionality of cells of all organs in the body $(125,126)$. Certainly, MELAS patients are deprived of post-translational modification in the wobble position of tRNA Leu (UUR), which is required for efficient decoding of both UUG and UUA involved in mitochondrial proteins of electron transport chain. However, the biosynthesis of mitochondria encoded proteins of MELAS patients is also diminished due to impaired aminoacylation rendering mitochondrial-encoded proteins more susceptible to the wobble defect. As a result, it is concluded that the aminoacylation defect of MELAS patients orchestrates the whole landscape of electron transport flux, reducing the activities of complexes I and III-V whereas wobble defect of taurine deficient subjects only causes diminished synthesis of complex I proteins.

Vionnet et al (127) proposed that the endocrine system was tightly associated with MELAS syndrome through the emergence of diabetes. Initially, researchers observed that $2 \%$ of type 2 diabetic patients harbored the primary MELAS-linked tRNA Leu(UUR) mutation. In particular, MELAS patients with type 2 diabetes exhibited impaired insulin secretion due to disturbance of pancreatic $\beta$ cells mimicking the glucose intolerance and impaired insulin secretion of type 2 diabetes patients (128). The metabolic pattern of MELAS patients with type 2 diabetes favored anaerobic metabolism (the enhanced conversion of glucose to lactate) than glucose oxidation, which is a predominant procedure of aerobic metabolism, thereby culminating in lactic acidosis. In other words, the accumulation of lactate was the direct result of increased $\mathrm{NADH} / \mathrm{NAD}^{+}$ratio and decreased respiratory chain activity since pyruvate is not easily incorporated in the citric acid cycle (125).

\section{Conclusions}

Taurine transport can be regulated at multiple levels, ranging from cellular stimuli to transcription factors. This explains why taurine transporter null mice display dysfunction in several tissue types. The impaired homeostasis of taurine transporter deficient mice has mainly been proposed to be ascribed to disturbed energy metabolism, as shown by a dysfunctional respiratory chain in various organs. Notably, the phenotype of taurine transporter null mice exerts various indiscernible similarities with a phenotype of mitochondrial diseases such as MELAS. These findings are of great significance, raising important questions for further research. It will be remarkably interesting to study the consequences of specific taurine transporter inactivation in single tissues, to better understand the function of the taurine transporter and in this manner to conclude if the phenotype of taurine transporter null mice is the result of synergistic interactions among organs. In the future, it is important to determine if the function of taurine transporter in one organ is sufficient to orchestrate the energy metabolism in all organs.

\section{Acknowledgements}

Not applicable.

\section{Funding}

This research was supported by I.K.Y State Scholarship Foundation for S. Baliou's Ph.D. studies. The IKY code is no. 2018-050-0502-13155.

\section{Availability of data and materials}

Not applicable.

\section{Authors' contributions}

All authors were involved in the conception and design of the study. SB performed the literature search, wrote the manuscript, critically analyzing the existing knowledge and designed the figures. SB, MG, AMK and VZ contributed to editing the manuscript concerning the regulation of TauT transporter; SB, MIP, DAS and VZ contributed to editing the manuscript concerning taurine deficient conditions. All the authors approved the final manuscript.

\section{Ethics approval and consent to participate}

Not applicable.

\section{Patient consent for publication}

Not applicable. 


\section{Competing interests}

DAS is the Editor-in-Chief for the journal, but had no personal involvement in the reviewing process, or any influence in terms of adjudicating on the final decision, for this article. The other authors declare that they have no competing interests.

\section{References}

1. Falany CN, Johnson MR, Barnes S and Diasio RB: Glycine and taurine conjugation of bile acids by a single enzyme. Molecular cloning and expression of human liver bile acid CoA:amino acid N-acyltransferase. J Biol Chem 269: 19375-19379, 1994.

2. Lambert IH, Jensen JV and Pedersen PA: mTOR ensures increased release and reduced uptake of the organic osmolyte taurine under hypoosmotic conditions in mouse fibroblasts. Am J Physiol Cell Physiol 306: C1028-C1040, 2014.

3. Espe $\mathrm{M}$ and Holen E: Taurine attenuates apoptosis in primary liver cells isolated from Atlantic salmon (Salmo salar). Br J Nutr 110: 20-28, 2013.

4. Trenkner E: Possible role of glutamate with taurine in neuron-glia interaction during cerebellar development. Prog Clin Biol Res 351: 133-140, 1990.

5. Schaffer SW, Azuma J and Madura JD: Mechanisms underlying taurine-mediated alterations in membrane function. Amino Acids 8: 231-246, 1995.

6. Tappaz ML: Taurine biosynthetic enzymes and taurine transporter: Molecular identification and regulations. Neurochem Res 29: 83-96, 2004.

7. Stipanuk MH: Role of the liver in regulation of body cysteine and taurine levels: A brief review. Neurochem Res 29: 105-110, 2004

8. Palkovits M, Elekes I, Láng T and Patthy A: Taurine levels in discrete brain nuclei of rats. J Neurochem 47: 1333-1335, 1986.

9. Stipanuk MH, Londono M, Lee JI, Hu M and Yu AF: Enzymes and metabolites of cysteine metabolism in nonhepatic tissues of rats show little response to changes in dietary protein or sulfur amino acid levels. J Nutr 132: 3369-3378, 2002.

10. Ueki I and Stipanuk MH: 3T3-L1 adipocytes and rat adipose tissue have a high capacity for taurine synthesis by the cysteine dioxygenase/cysteinesulfinate decarboxylase and cysteamine dioxygenase pathways. J Nutr 139: 207-214, 2009.

11. Ueki I and Stipanuk MH: Enzymes of the taurine biosynthetic pathway are expressed in rat mammary gland. J Nutr 137: $1887-1894,2007$

12. Park E, Park SY, Wang C, Xu J, LaFauci G and Schuller-Levis G: Cloning of murine cysteine sulfinic acid decarboxylase and its mRNA expression in murine tissues. Biochim Biophys Acta 1574: 403-406, 2002

13. Marcinkiewicz $\mathbf{J}$ and Kontny E: Taurine and inflammatory diseases. Amino Acids 46: 7-20, 2014.

14. Jerkins AA and Steele RD: Quantification of cysteine sulfinic acid decarboxylase in male and female rats: Effect of adrenalectomy and methionine. Arch Biochem Biophys 294: 534-538, 1992.

15. Ueki I, Roman HB, Valli A, Fieselmann K, Lam J, Peters R, Hirschberger LL and Stipanuk MH: Knockout of the murine cysteine dioxygenase gene results in severe impairment in ability to synthesize taurine and an increased catabolism of cysteine to hydrogen sulfide. Am J Physiol Endocrinol Metab 301: E668-E684, 2011.

16. Roman HB, Hirschberger LL, Krijt J, Valli A, Kožich V and Stipanuk MH: The cysteine dioxgenase knockout mouse: Altered cysteine metabolism in nonhepatic tissues leads to excess $\mathrm{H} 2 \mathrm{~S} / \mathrm{HS}(-)$ production and evidence of pancreatic and lung toxicity. Antioxid Redox Signal 19: 1321-1336, 2013.

17. Sturman JA: Taurine in development. J Nutr 118: 1169-1176, 1988.

18. Miyamoto Y, Tiruppathi C, Ganapathy V and Leibach FH: Active transport of taurine in rabbit jejunal brush-border membrane vesicles. Am J Physiol 257: G65-G72, 1989.

19. O'Flaherty L, Stapleton PP, Redmond HP and Bouchier-Hayes DJ: Intestinal taurine transport: A review. Eur J Clin Invest 27: 873-880, 1997.

20. Glass EN, Odle J and Baker DH: Urinary taurine excretion as a function of taurine intake in adult cats. J Nutr 122: 1135-1142, 1992.

21. Schuller-Levis G and Park E: Is taurine a biomarker. In: Advances in Clinical Chemistry. Vol 41. Elsevier, pp1-21, 2006.
22. Anderson CMH, Howard A, Walters JRF, Ganapathy V and Thwaites DT: Taurine uptake across the human intestinal brush-border membrane is via two transporters: $\mathrm{H}^{+}$-coupled PAT1 (SLC36A1) and $\mathrm{Na}^{+}-$and $\mathrm{Cl}^{-}$-dependent TauT (SLC6A6): intestinal taurine transport via PAT1 (SLC36A1) and TauT (SLC6A6). J Physiol 587: 731-744, 2009.

23. Voss JW, Pedersen SF, Christensen ST and Lambert IH: Regulation of the expression and subcellular localization of the taurine transporter TauT in mouse NIH3T3 fibroblasts. Eur J Biochem 271: 4646-4658, 2004.

24. Jensen A, Figueiredo-Larsen M, Holm R, Broberg ML, Brodin B and Nielsen CU: PAT1 (SLC36A1) shows nuclear localization and affects growth of smooth muscle cells from rats. Am J Physiol Endocrinol Metab 306: E65-E74, 2014.

25. Jong CJ, Ito T, Mozaffari M, Azuma J and Schaffer S: Effect of $\beta$-alanine treatment on mitochondrial taurine level and 5-taurinomethyluridine content. J Biomed Sci 17 (Suppl 1): S25, 2010.

26. Ubuka T, Okada A and Nakamura H: Production of hypotaurine from L-cysteinesulfinate by rat liver mitochondria. Amino Acids 35: 53-58, 2008

27. Suzuki T, Suzuki T, Wada T, Saigo K and Watanabe K: Taurine as a constituent of mitochondrial tRNAs: New insights into the functions of taurine and human mitochondrial diseases. EMBO J 21: 6581-6589, 2002.

28. Ögmundsdóttir MH, Heublein S, Kazi S, Reynolds B Visvalingam SM, Shaw MK and Goberdhan DCI: Proton-assisted amino acid transporter PAT1 complexes with Rag GTPases and activates TORC1 on late endosomal and lysosomal membranes. PLoS One 7: e36616, 2012.

29. Takeuchi K, Toyohara H and Sakaguchi M: A hyperosmotic stress-induced mRNA of carp cell encodes $\mathrm{Na}^{+}$- and $\mathrm{Cl}^{-}$-dependent high affinity taurine transporterl the sequence reported in this paper has been deposited in the DDBJ/EMBL/GenBank database with accession no. AB006986.1. Biochim Biophys Acta Biomembr 1464: 219-230, 2000.

30. Mollerup J and Lambert IH: Calyculin a modulates the kinetic constants for the $\mathrm{Na}^{+}$-coupled taurine transport in Ehrlich ascites tumour cells. Biochim Biophys Acta Biomembr 1371: 335-344, 1998.

31. Sakai S, Tosaka T, Tasaka J, Hashiguchi T and Yoshihama I: Taurine uptake by glial cells in the bullfrog sympathetic ganglia. Neurochem Int 14: 193-198, 1989.

32. Han X, Patters AB, Jones DP, Zelikovic I and Chesney RW: The taurine transporter: Mechanisms of regulation. Acta Physiol (Oxf) 187: 61-73, 2006.

33. Heller-Stilb B, van Roeyen C, Rascher K, Hartwig HG, Huth A, Seeliger MW, Warskulat U and Häussinger D: Disruption of the taurine transporter gene (taut) leads to retinal degeneration in mice. FASEB J 16: 231-233, 2002.

34. Han X, Patters AB and Chesney RW: Transcriptional repression of taurine transporter gene (TauT) by p53 in renal cells. J Biol Chem 277: 39266-39273, 2002.

35. Lambert IH: Regulation of the cellular content of the organic osmolyte taurine in mammalian cells. Neurochem Res 29: 27-63, 2004.

36. Miyazaki T and Matsuzaki Y: Taurine and liver diseases: A focus on the heterogeneous protective properties of taurine. Amino Acids 46: 101-110, 2014

37. Hammarqvist F, Angsten G, Meurling S, Andersson K and Wernerman J: Age-related changes of muscle and plasma amino acids in healthy children. Amino Acids 39: 359-366, 2010.

38. Li Y, Hu Z, Chen B, Bu Q, Lu W, Deng Y, Zhu R, Shao X, Hou J, Zhao J, et al: Taurine attenuates methamphetamine-induced autophagy and apoptosis in PC12 cells through mTOR signaling pathway. Toxicol Lett 215: 1-7, 2012

39. Holecek M and Sispera L: Effects of arginine supplementation on amino acid profiles in blood and tissues in fed and overnight-fasted rats. Nutrients 8: 206, 2016.

40. Li Y, Li F, Wu L, Wei H, Liu Y, Li T, Tan B, Kong X, Yao K, Chen $\mathrm{S}$, et al: Effects of dietary protein restriction on muscle fiber characteristics and mTORC1 pathway in the skeletal muscle of growing-finishing pigs. J Anim Sci Biotechnol 7: 47, 2016.

41. Holecek M and Kovarik M: Alterations in protein metabolism and amino acid concentrations in rats fed by a high-protein (casein-enriched) diet - effect of starvation. Food Chem Toxicol 49: 3336-3342, 2011.

42. Chen X, Sebastian BM, Tang H, McMullen MM, Axhemi A, Jacobsen DW and Nagy LE: Taurine supplementation prevents ethanol-induced decrease in serum adiponectin and reduces hepatic steatosis in rats. Hepatology 49: 1554-1562, 2009. 
43. Mochizuki T, Satsu H, Nakano T and Shimizu M: Regulation of the human taurine transporter by TNF- $\alpha$ and an anti-inflammatory function of taurine in human intestinal Caco-2 cells. Biofactors 21: 141-144, 2004

44. Ishizuka K, Miyamoto Y, Satsu H, Sato R and Shimizu M: Characteristics of lysophosphatidylcholine in its inhibition of taurine uptake by human intestinal Caco-2 cells. Biosci Biotechnol Biochem 66: 730-736, 2002.

45. Mochizuki T, Satsu H and Shimizu M: Signaling pathways involved in tumor necrosis factor $\alpha$-induced upregulation of the taurine transporter in Caco-2 cells. FEBS Lett 579: 3069-3074, 2005.

46. Merheb M, Daher RT, Nasrallah M, Sabra R, Ziyadeh FN and Barada K: Taurine intestinal absorption and renal excretion test in diabetic patients: A pilot study. Diabetes Care 30: 2652-2654, 2007.

47. Han X, Budreau AM and Chesney RW: The taurine transporter gene and its role in renal development. Amino Acids 19: 499-507, 2000.

48. Chesney RW, Scriver CR and Mohyuddin F: Localization of the membrane defect in transepithelial transport of taurine by parallel studies in vivo and in vitro in hypertaurinuric mice. J Clin Invest 57: 183-193, 1976.

49. Satsu H, Miyamoto Y and Shimizu M: Hypertonicity stimulates taurine uptake and transporter gene expression in Caco-2 cells. Biochim Biophys Acta 1419: 89-96, 1999.

50. Uchida S, Kwon HM, Yamauchi A, Preston AS, Marumo F and Handler JS: Molecular cloning of the cDNA for an MDCK cell $\mathrm{Na}(+)$ - and $\mathrm{Cl}(-)$-dependent taurine transporter that is regulated by hypertonicity. Proc Natl Acad Sci USA 89: 8230-8234, 1992.

51. Pramod AB, Foster J, Carvelli L and Henry LK: SLC6 transporters: Structure, function, regulation, disease association and therapeutics. Mol Aspects Med 34: 197-219, 2013.

52. Kubo Y, Akanuma SI and Hosoya KI: Impact of SLC6A transporters in physiological taurine transport at the blood-retinal barrier and in the liver. Biol Pharm Bull 39: 1903-1911, 2016.

53. Zelikovic I and Chesney RW: Sodium-coupled amino acid transport in renal tubule. Kidney Int 36: 351-359, 1989.

54. Silbernagl S: The renal handling of amino acids and oligopeptides. Physiol Rev 68: 911-1007, 1988.

55. Zelikovic I and Chesney RW: Ionic requirements for amino acid transport. Am J Kidney Dis 14: 313-316, 1989.

56. Hoffmann EK and Lambert IH: Amino acid transport and cell volume regulation in Ehrlich ascites tumour cells. J Physiol 338: 613-625, 1983

57. Han X, Budreau AM and Chesney RW: Identification of promoter elements involved in adaptive regulation of the taurine transporter gene: Role of cytosolic $\mathrm{Ca}^{2+}$ signaling. Adv Exp Med Biol 483: 535-544, 2000.

58. Wójcik OP, Koenig KL, Zeleniuch-Jacquotte A, Costa M and Chen Y: The potential protective effects of taurine on coronary heart disease. Atherosclerosis 208: 19-25, 2010.

59. Jones DP, Miller LA and Chesney RW: Polarity of taurine transport in cultured renal epithelial cell lines: LLC-PK1 and MDCK. Am J Physiol 265: F137-F145, 1993.

60. Jones DP, Miller LA, Dowling C and Chesney RW: Regulation of taurine transporter activity in LLC-PK1 cells: Role of protein synthesis and protein kinase C activation. J Am Soc Nephrol 2: 1021-1029, 1991.

61. Jones DP, Miller LA and Chesney RW: Adaptive regulation of taurine transport in two continuous renal epithelial cell lines. Kidney Int 38: 219-226, 1990.

62. Jones DP, Miller LA, Budreau A and Chesney RW: Characteristics of taurine transport in cultured renal epithelial cell lines: asymmetric polarity of proximal and distal cell lines. Adv Exp Med Biol 315: 405-411, 1992.

63. Handler JS and Kwon HM: Transcriptional regulation by changes in tonicity. Kidney Int 60: 408-411, 2001.

64. Ito T, Fujio Y, Schaffer SW and Azuma J: Involvement of transcriptional factor TonEBP in the regulation of the taurine transporter in the cardiomyocyte. Adv Exp Med Biol 643: 523-532, 2009

65. Ito T, Fujio Y, Hirata M, Takatani T, Matsuda T, Muraoka S, Takahashi K and Azuma J: Expression of taurine transporter is regulated through the TonE (tonicity-responsive element)/TonEBP (TonE-binding protein) pathway and contributes to cytoprotection in HepG2 cells. Biochem J 382: 177-182, 2004.

66. Ortells MC, Morancho B, Drews-Elger K, Viollet B, Laderoute KR, López-Rodríguez $\mathrm{C}$ and Aramburu J: Transcriptional regulation of gene expression during osmotic stress responses by the mammalian target of rapamycin. Nucleic Acids Res 40: 4368-4384, 2012.
67. Roos S, Kanai Y, Prasad PD, Powell TL and Jansson T: Regulation of placental amino acid transporter activity by mammalian target of rapamycin. Am J Physiol Cell Physiol 296: C142-C150, 2009.

68. Han X and Chesney RW: The role of taurine in renal disorders. Amino Acids 43: 2249-2263, 2012.

69. Han X, Yue J and Chesney RW: Functional TauT protects against acute kidney injury. J Am Soc Nephrol 20: 1323-1332, 2009.

70. Matsell DG, Bennett T, Han X, Budreau AM and Chesney RW: Regulation of the taurine transporter gene in the S3 segment of the proximal tubule. Kidney Int 52: 748-754, 1997.

71. Shalby AB, Assaf N and Ahmed HH: Possible mechanisms for $\mathrm{N}$-acetyl cysteine and taurine in ameliorating acute renal failure induced by cisplatin in rats. Toxicol Mech Methods 21: 538-546, 2011.

72. Han X: Targeting taurine transporter (TauT) for cancer immunotherapy of p53 mutation mediated cancers - molecular basis and preclinical implication. Adv Exp Med Biol 1155: 543-553, 2019.

73. Hansen DB, Friis MB, Hoffmann EK and Lambert IH: Downregulation of the taurine transporter TauT during hypo-osmotic stress in NIH3T3 mouse fibroblasts. J Membr Biol 245: 77-87, 2012.

74. Mollerup J and Lambert IH: Phosphorylation is involved in the regulation of the taurine influx via the $\beta$-system in Ehrlich ascites tumor cells. J Membr Biol 150: 73-82, 1996.

75. Qian X, Vinnakota S, Edwards C and Sarkar HK: Molecular characterization of taurine transport in bovine aortic endothelial cells. Biochim Biophys Acta 1509: 324-334, 2000.

76. Jacobsen JH, Clement CA, Friis MB and Lambert IH: Casein kinase 2 regulates the active uptake of the organic osmolyte taurine in NIH3T3 mouse fibroblasts. Pflugers Arch 457: 327-337, 2008.

77. Smith KE, Borden LA, Wang CH, Hartig PR, Branchek TA and Weinshank RL: Cloning and expression of a high affinity taurine transporter from rat brain. Mol Pharmacol 42: 563-569, 1992.

78. Kang YS, Ohtsuki S, Takanaga H, Tomi M, Hosoya K and Terasaki T: Regulation of taurine transport at the blood-brain barrier by tumor necrosis factor- $\alpha$, taurine and hypertonicity. J Neurochem 83: 1188-1195, 2002.

79. Frank RN: Diabetic retinopathy. N Engl J Med 350: 48-58, 2004.

80. Lorenzi M, Healy DP, Hawkins R, Printz JM and Printz MP: Studies on the permeability of the blood-brain barrier in experimental diabetes. Diabetologia 29: 58-62, 1986.

81. Schoch HJ, Fischer S and Marti HH: Hypoxia-induced vascular endothelial growth factor expression causes vascular leakage in the brain. Brain 125: 2549-2557, 2002.

82. Yeh WL, Lu DY, Lin CJ, Liou HC and Fu WM: Inhibition of hypoxia-induced increase of blood-brain barrier permeability by $\mathrm{YC}-1$ through the antagonism of HIF-1 $\alpha$ accumulation and VEGF expression. Mol Pharmacol 72: 440-449, 2007.

83. Nicholson BP and Schachat AP: A review of clinical trials of anti-VEGF agents for diabetic retinopathy. Graefes Arch Clin Exp Ophthalmol 248: 915-930, 2010.

84. Poulaki V, Qin W, Joussen AM, Hurlbut P, Wiegand SJ, Rudge J, Yancopoulos GD and Adamis AP: Acute intensive insulin therapy exacerbates diabetic blood-retinal barrier breakdown via hypoxia-inducible factor-1 $\alpha$ and VEGF. J Clin Invest 109: 805-815, 2002.

85. Napoli Z, Seghieri G, Bianchi L, Anichini R, De Bellis A, Campesi I, Carru C, Occhioni S, Zinellu A and Franconi F: Taurine transporter gene expression in mononuclear blood cells of type 1 diabetes patients. J Diabetes Res 2016: 7313162, 2016.

86. Bianchi L, Lari R, Anichini R, De Bellis A, Berti A, Napoli Z, Seghieri G and Franconi F: Taurine transporter gene expression in peripheral mononuclear blood cells of type 2 diabetic patients. Amino Acids 42: 2267-2274, 2012.

87. Han X and Chesney RW: Knockdown of TauT expression impairs human embryonic kidney 293 cell development. Adv Exp Med Biol 776: 307-320, 2013.

88. Son HY, Kim H and Kwon YH: Taurine prevents oxidative damage of high glucose-induced cataractogenesis in isolated rat lenses. J Nutr Sci Vitaminol (Tokyo) 53: 324-330, 2007.

89. Hou X, Wang Z, Ding F, He Y, Wang P, Liu X, Xu F, Wang J and Yang Y: Taurine transporter regulates adipogenic differentiation of human adipose-derived stem cells through affecting Wnt $/ \beta$-catenin signaling pathway. Int J Biol Sci 15: 1104-1112, 2019.

90. Tervaert TWC, Mooyaart AL, Amann K, Cohen AH, Cook HT, Drachenberg CB, Ferrario F, Fogo AB, Haas M, de Heer E, et al; Renal Pathology Society: Pathologic classification of diabetic nephropathy. J Am Soc Nephrol 21: 556-563, 2010. 
91.Lang PA, Warskulat U, Heller-Stilb B, Huang DY, Grenz A, Myssina S, Duszenko M, Lang F, Häussinger D, Vallon V, et al: Blunted apoptosis of erythrocytes from taurine transporter deficient mice. Cell Physiol Biochem 13: 337-346, 2003.

92. Villumsen KR, Duelund L and Lambert IH: Acute cholesterol depletion leads to net loss of the organic osmolyte taurine in Ehrlich Lettré tumor cells. Amino Acids 39: 1521-1536, 2010.

93. Lambert IH, Nielsen JH, Andersen HJ and Ørtenblad N: Cellular model for induction of drip loss in meat. J Agric Food Chem 49: 4876-4883, 2001.

94.Poulsen KA, Andersen EC, Hansen CF, Klausen TK, Hougaard C, Lambert IH and Hoffmann EK: Deregulation of apoptotic volume decrease and ionic movements in multidrug-resistant tumor cells: Role of chloride channels. Am J Physiol Cell Physiol 298: C14-C25, 2010.

95.Lambert IH: Effect of arachidonic acid on conductive $\mathrm{Na}, \mathrm{K}$ and anion transport in Ehlrich ascites tumor cells under isotonic and hypotonic conditions. Cell Physiol Biochem 1: 177-194, 1991.

96. Lambert IH: Effect of arachidonic acid, fatty acids, prostaglandins, and leukotrienes on volume regulation in Ehrlich ascites tumor cells. J Membr Biol 98: 207-221, 1987.

97.Lambert IH: Reactive oxygen species regulate swelling-induced taurine efflux in NIH3T3 mouse fibroblasts. J Membr Biol 192: $19-32,2003$

98. Ito T, Kimura Y, Uozumi Y, Takai M, Muraoka S, Matsuda T, Ueki K, Yoshiyama M, Ikawa M, Okabe M, et al: Taurine depletion caused by knocking out the taurine transporter gene leads to cardiomyopathy with cardiac atrophy. J Mol Cell Cardiol 44: 927-937, 2008

99. Izumi K, Kishita C, Nakagawa K, Huxtable RJ, Shimizu T, Koja T and Fukuda T: Modification of the antiepileptic actions of phenobarbital and phenytoin by the taurine transport inhibitor guanidinoethane sulfonate. Eur J Pharmacol 110: 219-224, 1985.

100. Schaffer SW, Shimada-Takaura K, Jong CJ, Ito T and Takahashi K: Impaired energy metabolism of the taurine deficient heart. Amino Acids 48: 549-558, 2016.

101. Choi D, Kim SJ, Kwon DY, Lee SY and Kim YC: Taurine depletion by beta-alanine inhibits induction of hepatotoxicity in mice treated acutely with carbon tetrachloride. Adv Exp Med Biol 643: 305-311, 2009.

102. Warskulat U, Flögel U, Jacoby C, Hartwig HG, Thewissen M, Merx MW, Molojavyi A, Heller-Stilb B, Schrader J and Häussinger D: Taurine transporter knockout depletes muscle taurine levels and results in severe skeletal muscle impairment but leaves cardiac function uncompromised. FASEB J 18 577-579, 2004.

103.Lötsch J, Hummel T, Warskulat U, Coste O, Häussinger D, Geisslinger $\mathrm{G}$ and Tegeder I: Congenital taurine deficiency in mice is associated with reduced sensitivity to nociceptive chemical stimulation. Neuroscience 259: 63-70, 2014.

104.Ito T, Oishi S, Takai M, Kimura Y, Uozumi Y, Fujio Y, Schaffer SW and Azuma J: Cardiac and skeletal muscle abnormality in taurine transporter-knockout mice. J Biomed Sci 17 (Suppl 1): S20, 2010.

105. Kaesler S, Sobiesiak M, Kneilling M, Volz T, Kempf WE, Lang PA, Lang KS, Wieder T, Heller-Stilb B, Warskulat U, et al: Effective T-cell recall responses require the taurine transporter Taut. Eur J Immunol 42: 831-841, 2012

106. Warskulat U, Borsch E, Reinehr R, Heller-Stilb B, Mönnighoff I, Buchczyk D, Donner M, Flögel U, Kappert G, Soboll S, et al Chronic liver disease is triggered by taurine transporter knockout in the mouse. FASEB J 20: 574-576, 2006.

107. Warskulat U, Borsch E, Reinehr R, Heller-Stilb B, Roth C, Witt $\mathrm{M}$ and Häussinger D: Taurine deficiency and apoptosis: Findings from the taurine transporter knockout mouse. Arch Biochem Biophys 462: 202-209, 2007.

108. Qvartskhava N, Jin CJ, Buschmann T, Albrecht U, Bode JG, Monhasery N, Oenarto J, Bidmon HJ, Görg B and Häussinger D Taurine transporter (TauT) deficiency impairs ammonia detoxification in mouse liver. Proc Natl Acad Sci USA 116: 6313-6318, 2019.

109. Ito T, Okazaki K, Nakajima D, Shibata D, Murakami S and Schaffer S: Mass spectrometry-based metabolomics to identify taurine-modified metabolites in heart. Amino Acids 50: 117-124, 2018.
110. Franchi-Gazzola R, Gaccioli F, Bevilacqua E, Visigalli R, Dall'Asta V, Sala R, Varoqui H, Erickson JD, Gazzola GC and Bussolati O: The synthesis of SNAT2 transporters is required for the hypertonic stimulation of system a transport activity. Biochim Biophys Acta Biomembr 1667: 157-166, 2004.

111. Trama J, Go WY and Ho SN: The osmoprotective function of the NFAT5 transcription factor in T cell development and activation. J Immunol 169: 5477-5488, 2002.

112. Burg MB and Ferraris JD: Intracellular organic osmolytes: Function and regulation. J Biol Chem 283: 7309-7313, 2008.

113. Schaffer SW, Jong CJ, Ito T and Azuma J: Role of taurine in the pathologies of MELAS and MERRF. Amino Acids 46: 47-56, 2014.

114. Board PG, Moore KA and Smith JE: Purification and properties of $\gamma$-glutamylcyclotransferase from human erythrocytes. Biochem J 173: 427-431, 1978

115. Krishnamurthy J, Torrice C, Ramsey MR, Kovalev GI, Al-Regaiey K, Su L and Sharpless NE: Ink4a/Arf expression is a biomarker of aging. J Clin Invest 114: 1299-1307, 2004

116. Ito T, Yoshikawa N, Inui T, Miyazaki N, Schaffer SW and Azuma J: Tissue depletion of taurine accelerates skeletal muscle senescence and leads to early death in mice. PLoS One 9: e107409, 2014

117. Back SH, Scheuner D, Han J, Song B, Ribick M, Wang J, Gildersleeve RD, Pennathur S and Kaufman RJ: Translation attenuation through eIF $2 \alpha$ phosphorylation prevents oxidative stress and maintains the differentiated state in $\beta$ cells. Cell Metab 10: 13-26, 2009.

118. Harding HP, Novoa I, Zhang Y, Zeng H, Wek R, Schapira M and Ron D: Regulated translation initiation controls stress-induced gene expression in mammalian cells. Mol Cell 6: 1099-1108, 2000.

119. Araki K and Nagata K: Protein folding and quality control in the ER. Cold Spring Harb Perspect Biol 4: a015438-a015438, 2012.

120. Salminen A and Kaarniranta K: ER stress and hormetic regulation of the aging process. Ageing Res Rev 9: 211-217, 2010.

121. Jong CJ, Ito T, Azuma J and Schaffer S: Taurine depletion decreases GRP78 expression and downregulates Perk-dependent activation of the unfolded protein response. Adv Exp Med Biol 803: 571-579 2015

122. Ito T, Yamamoto N, Nakajima S and Schaffer SW: Beta-catenin and SMAD3 are associated with skeletal muscle aging in the taurine transporter knockout mouse. Adv Exp Med Biol 975 (Pt 1): 497-502, 2017.

123. Kirino Y, Yasukawa T, Ohta S, Akira S, Ishihara K, Watanabe K and Suzuki T: Codon-specific translational defect caused by a wobble modification deficiency in mutant tRNA from a human mitochondrial disease. Proc Natl Acad Sci USA 101: 15070-15075, 2004

124. Yasukawa T, Suzuki T, Ueda T, Ohta S and Watanabe K: Modification defect at anticodon wobble nucleotide of mitochondrial tRNAs(Leu)(UUR) with pathogenic mutations of mitochondrial myopathy, encephalopathy, lactic acidosis, and stroke-like episodes. J Biol Chem 275: 4251-4257, 2000.

125. Mozaffari MS, Tan BH, Lucia MA and Schaffer SW: Effect of drug-induced taurine depletion on cardiac contractility and metabolism. Biochem Pharmacol 35: 985-989, 1986.

126. Jong CJ, Azuma J and Schaffer S: Mechanism underlying the antioxidant activity of taurine: Prevention of mitochondrial oxidant production. Amino Acids 42: 2223-2232, 2012.

127. Vionnet N, Passa P and Froguel P: Prevalence of mitochondrial gene mutations in families with diabetes mellitus. Lancet 342 : 1429-1430, 1993.

128. Maassen JA, 'T Hart LM, Van Essen E, Heine RJ, Nijpels G, Jahangir Tafrechi RSJ, Raap AK, Janssen GMC and Lemkes HHPJ: Mitochondrial diabetes: Molecular mechanisms and clinical presentation. Diabetes 53 (Suppl 1): S103-S109, 2004.

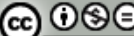

This work is licensed under a Creative Commons Attribution-NonCommercial-NoDerivatives 4.0 International (CC BY-NC-ND 4.0) License. 